\title{
Diaphragm fenestration for chylothorax: Full of holes?
}

\author{
Thomas S. Maxey, MD
}

\author{
From the Department of Pediatric Cardiac Surgery, The Congenital Heart Center at Levine Children's Hospital, \\ Charlotte, NC. \\ Disclosures: Author has nothing to disclose with regard to commercial support. \\ Received for publication Aug 29, 2017; accepted for publication Aug 30, 2017; available ahead of print Oct 5 , \\ 2017. \\ Address for reprints: Thomas S. Maxey, MD, The Congenital Heart Center at Levine Children's Hospital, 1001 \\ Blythe Blvd, Suite 200, Charlotte, NC 28207 (E-mail: Thomas.maxey@ carolinashealthcare.org). \\ J Thorac Cardiovasc Surg 2017;154:2069 \\ $0022-5223 / \$ 36.00$ \\ Copyright (C) 2017 by The American Association for Thoracic Surgery \\ https://doi.org/10.1016/j.jtcvs.2017.08.113
}

Fortunately, chylothorax is an infrequent problem in children after congenital heart surgery. Unfortunately, postoperative chylothorax is often a clinical challenge that carries significant morbidity. Although I have seen chylothorax with the full spectrum of congenital heart disease, it typically occurs with aortic arch surgery and after cavopulmonary connections. The etiology is iatrogenic, traumatic disruption of the thoracic duct or the lymphatic pathways and the incidence varies significantly. The treatment algorithm also varies greatly, from conservative medical management to surgical intervention. Regardless of the treatment strategy, certain principles remain constant: decreasing chyle production, draining and obliterating the pleural space, maintaining adequate nutrition and volume status, and instituting necessary respiratory care.

Kumar and colleagues ${ }^{1}$ at the University of Tennessee have convincingly described their strategy in treating postoperative chylothorax with diaphragm fenestration after congenital heart surgery in a relatively young patient population. Appropriately, the study excluded patients with coarctation repair through a left thoracotomy. As encouraging as their results seem, most contemporary congenital heart centers would find it difficult to adopt the strategy of right-sided fenestration after coarctation repair. I have no doubt that every institution has a specific style or algorithm when dealing with postoperative, high-output chylothorax: what oral formula to use, when to convert to parenteral nutrition, when to start somatostatin or its analog octreotide, and whether to use steroids. Neither Kumar and colleagues ${ }^{1}$ nor I intend to change the subtle differences in conservative medical management in the initial phases of managing postoperative chylothorax.

The timing and indication of surgical intervention, and now the type of operation (thoracic duct ligation, pleuroperitoneal shunt, pleurodesis and drainage, and diaphragm fenestration), may, unfortunately, add to further variation in the management of chylothorax. Regardless of surgical strategy, it is crucial to evaluate thoroughly possible causes of systemic venous hypertension, because increased rightwill give it a try.

\section{Reference}

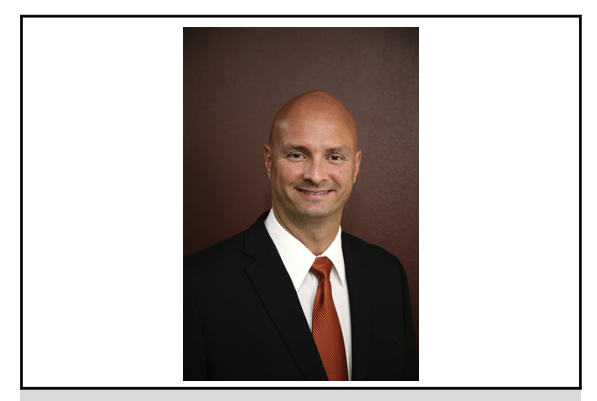

Thomas S. Maxey, MD

Central Message

Results of diaphragm fenestration in the management algorithm for postoperative chylothorax are encouraging. It appears safe and effective, but it may add to further variation in treatment strategies.

See Article page 2062.

sided cardiac pressure hinders spontaneous closure of traumatized lymphatic vessels and is associated with failure of conservative therapy. Most centers, including my own, do not consider any surgical intervention before 4 to 6 weeks of unsuccessful conservative therapy. The authors reported success appears to challenge the more traditional algorithm, with 5 of their 8 patients returning to the operating room within 3 weeks for surgical intervention. Two of their patients underwent fenestration within 1 week of conservative management (postoperative days 4 and 6). Although their results are encouraging, with resolution of effusion and the chest tube removal generally within 4 days, I am not sure that I am ready to consider conservative management a failure within 1 week.

Kumar and colleagues ${ }^{1}$ have demonstrated the safety and efficacy of diaphragm fenestration in a difficult patient population that we all face. As I think more about the struggles and treatment inconsistencies that many surgeons have with chylothorax, I am encouraged by at least another-and apparently more reliable_-surgical option. I must admit, on my initial review of the article, I thought it was "full of holes." After some thought and review of my own experience with surgical intervention for chylothorax, however, I

1. Kumar TK, Balduf K, Boston U, Knott-Craig C. Diaphragmatic fenestration for refractory chylothorax after congenital cardiac surgery in infants. J Thorac Cardiovasc Surg. 2017;154:2062-8. 